(C) 2017, Elsevier. Licensed under the Creative Commons Attribution-

NonCommercial-NoDerivatives 4.0 International

http://creativecommons.org/licenses/by-nc-nd/4.0/

\title{
Every saint has a past, and every sinner has a future: Influences of regulatory focus on consumers' moral self-regulation
}

\author{
Maria Schwabe ${ }^{\mathrm{a}}$, David B. Dose ${ }^{\mathrm{b}}$, and Gianfranco Walsh ${ }^{\mathrm{a}}$ \\ ${ }^{a}$ Friedrich Schiller University of Jena, Jena, Germany \\ ${ }^{b}$ Aston Business School, Aston University, Birmingham, United Kingdom
}

December 2017; accepted for publication in Special Issue Morality in the Marketplace, Journal of Consumer Psychology

Corresponding author:

Maria Schwabe

Friedrich-Schiller-University of Jena

Chair of General Management and Marketing

Carl-Zeiss-Strasse 3

Jena, 07743 Germany

Tel: +49 (0) 3641 943114Fax: +49 (0) 3641943112

E-mail addresses:

maria.schwabe@uni-jena.de (Maria Schwabe),

d.dose@aston.ac.uk (David B. Dose),

walsh@uni-jena.de (Gianfranco Walsh)

\section{Author Note:}

This research did not receive any specific grant from funding agencies in the public, commercial, or not-for-profit sectors. 


\begin{abstract}
Moral decisions in the marketplace largely depend on consumers' own behavioral history. Psychology literature distinguishes two possible routes for consumers' sequential moral decision making: moral balancing and moral consistency. Moral balancing refers to consumers' deviation from the moral stance reflected in their past decisions; moral consistency implies that consumers repeat their prior moral and immoral decisions. Drawing on regulatory focus theory, four experimental studies affirm that balancing effects occur for consumers with a strong promotion focus, but consistency is more pronounced for prevention-focused consumers; the studies also elucidate the processes underlying these effects. In addition, the promotion-balancing effect, but not the prevention-repetition effect, disappears if the second decision is unambiguously moral or immoral. These findings contribute to a better understanding of morality in the marketplace by showing that the prevention-repetition effect from psychology literature arises in consumption situations, and the promotion-balancing effect emerges as a new consumer behavior phenomenon.
\end{abstract}

Keywords: regulatory focus, moral self-regulation, moral licensing, moral cleansing, moral consistency, moral consumption 
Moral decisions in the marketplace are not made in isolation; they depend on prior moral decisions (Zhang, Cornwell, \& Higgins, 2014; Zhong, Liljenquist, \& Cain, 2009). Sequential moral decisions may feature conflicts, between acting morally and pursuing one's self-interest in initial versus subsequent decisions (Huber, Goldmith, \& Mogilner, 2008), such that consumers constantly calibrate their moral stances (Zhong et al., 2009). For example, consumers trade off today's purchase of inexpensive, conventional groceries against more expensive, environmentally responsible products, or the future benefit of donating money to charity versus the pleasure of spending money on themselves.

Prior research proposes two possible routes for, and thus theoretical viewpoints regarding, consumers' sequential moral decision making (e.g., Huber et al., 2008): moral balancing and moral consistency. Moral balancing means that consumers deviate from the moral stance reflected in their past decisions, such that they balance their moral and immoral decisions and act more morally after an initial immoral decision and more immorally after previous moral behavior (Conway \& Peetz, 2012; Gneezy, Imas, Brown, Nelson, \& Norton, 2012; Jeong \& Koo, 2015; Sachdeva, Iliev, \& Medin, 2009). For example, consumers may donate less money to a charity after buying cause-related products (Krishna, 2011), are more likely to cheat and lie after buying green products (Mazar \& Zhong, 2010), and tend to prefer hedonic over utilitarian products after volunteering or donating (Khan \& Dhar, 2006).

In contrast, moral consistency implies that consumers persist with their moral history, and with this consistent behavior, people act more morally after prior moral decisions and more immorally after an initial immoral decision (Gawronski \& Strack, 2012; Gino, Norton, \& Ariely, 2010). Karmarkar and Bollinger (2015), for example, show that retail shoppers who bring their own bags to the store purchase more organic products, and Cornelissen, Pandelaere, Warlop, and Dewitte (2008) reveal that reminding consumers of their past environmentally friendly behaviors 
increases their probability of choosing environmentally friendly products subsequently. Although research thus has identified and examined both moral self-regulation routes, the question of when and why past behavior induces consumers to be consistent or else licenses them to balance out their behavior remains under-researched (Blanken, van de Ven, \& Zeelenberg, 2015; Merritt, Effron, \& Monin, 2010).

Zhang et al. (2014) made some strides in understanding sequential moral decision making. Building on regulatory focus theory (RFT), they establish a prevention-repetition effect in different ethical (but not consumption-related) domains, noting that people with a strong prevention focus repeat both their prior moral and immoral behaviors in subsequent decisions. However, they find no effect of initial decisions on subsequent behavior among promotionfocused participants. Zhang et al. theorize (but do not empirically test) that the preventionrepetition effect is based on prevention-focused people's motivation to maintain the status quo established by a prior decision. Despite these intriguing findings, there is limited understanding of when and why regulatory focus influences consumers' moral self-regulation and thus their consumption behavior.

We attempt to contribute such an understanding of consumers' moral self-regulation (i.e., moral balancing and moral consistency) by building on and extending Zhang et al.'s (2014) findings. First, drawing on RFT, we reveal that the prevention-repetition effect they report arises in moral consumption situations too. We shed light on the mechanism underlying this effect and empirically test the mediating role of motivation to maintain the status quo. We find that prior moral and immoral decisions increase prevention-focused consumers' motivation to maintain the status quo, resulting in morally congruent subsequent consumption behavior. This study offers the first empirical examination of the mediating role of consumers' motivation to maintain the status quo in relation to moral self-regulation. 
Second, we add to recent literature on moral balancing by showing that the balancing effect occurs only for promotion-focused consumers; within this group, the balancing effect also is contingent on the moral ambiguity of the target behavior, or whether the subsequent decision is unequivocally or ambiguously moral or immoral. In particular, moral balancing occurs for consumers with a strong promotion focus but not for those with a strong prevention focus, yet the balancing effect also disappears for promotion-focused consumers if the target behavior (i.e., second decision) is unambiguously moral or immoral. With this finding, we help explain the low effect sizes of moral balancing, such as Blanken et al.'s (2015) meta-analytical finding of an average effect size of Cohen's $d=.31$ for the moral licensing effect. Our results also can explain non-significant balancing effects among promotion-focused people in psychology literature (Zhang et al., 2014).

Third, we identify and test the mechanism underlying the moral balancing effect for promotion-focused consumers. After their prior moral behavior, promotion-focused consumers perceive progress toward the goal of having a moral self-image, which licenses their subsequent ambiguous transgressions. An initial immoral decision negatively influences their goal progress though, leading to compensatory (i.e., more moral) behavior thereafter (moral cleansing). Overall, this research contributes to a better understanding of consumers' moral self-regulation in the marketplace. Accordingly, we first briefly discuss consumers' moral self-regulation and the role of regulatory focus, as well as a moderating and two mediating factors. Then, we derive our hypotheses and provide an overview of our four experimental studies. We next turn to the experiments and conclude with a discussion of our findings. 


\section{Theoretical background and hypotheses development}

\section{Moral consumption behavior and consumers' moral self-regulation}

In (moral) consumption situations, consumers often face a trade-off between contributing to the welfare of others (e.g., paying a higher price for a fair trade food product to ensure farmers make a livable income) and pursuing their own self-interests (e.g., paying a lower price for a conventional product; Aquino, Freeman, Reed, Lim, \& Felps, 2009; Joosten, van Dijke, Van Hiel, \& De Cremer, 2014). In this context, moral consumption behavior demonstrates "social responsiveness to the needs and interests of others" (Aquino et al., 2009, p. 124) and "benefits the welfare of others, the environment, or society as a whole" (Susewind \& Hoelzl, 2014, p. 201). Purchasing green products thus is perceived as more moral than selecting conventional products (Eskine, 2013; Karmarkar \& Bollinger, 2015; Mazar \& Zhong, 2010; Susewind \& Hoelzl, 2014) because green products benefit the environment more. With this definition, we also predict that moral consumption behavior can take the form of donating to charity instead of keeping money for oneself, honestly reporting undercharges on a bill to a service employee, or purchasing clothing made from recycled materials for a higher price than conventional clothing. In contrast, pursuing one's self-interests rather than considering the welfare of others is considered less moral or even immoral (Aquino et al., 2009; Susewind \& Hoelzl, 2014). In line with this conceptualization, Mazar and Zhong (2010) show that purchasing conventional products can be established as less moral than selecting green products.

The desire to act in a moral way and keep a positive moral self-view is inherent to most consumers (Mazar, Amir, \& Ariely, 2008; Mazar \& Zhong, 2010) though not always reflected in actual consumer behavior. Consumers have competing goals and self-regulate their moral consumption behavior, which involves moving toward or away from goals, following an internal guidance system (Carver \& Scheier, 2001). In this process, past decisions influence subsequent 
consumption behavior through two alternative, equally important routes (Huber et al., 2008). The moral consistency route suggests that people repeat their past decisions, regardless of whether they were pleasant or unpleasant (e.g., Ariely, 2008; Gawronski \& Strack, 2012). The moral balancing route suggests behavior in one moral direction leads consumers to behave in opposite moral directions subsequently (e.g., Jeong \& Koo, 2015; Khan \& Dhar, 2006; Mazar \& Zhong, 2010). The route that consumers follow likely is driven by their internal guidance system, specifically, their inherent or induced self-regulatory system.

\section{Regulatory focus as a motivational principle in moral self-regulation}

Regulatory focus theory proposes that a person's regulatory focus, as a strategic orientation for approaching goals, has important consequences for self-regulative processes (Chernev, 2004; Higgins, 1997, 2002). It distinguishes two self-regulatory systems: a promotion focus that centers on achieving aspirations, advancement, and gains, and a prevention focus that is associated with goals of safety, responsibilities, and non-losses. These distinct self-regulatory systems result in different self-regulation processes, depending on whether they get activated by vigilant avoidance strategies (prevention) or eager approach strategies (promotion) (Higgins, 1997). In turn, we

propose that their regulatory focus influences whether consumers strive for advancement (and balance their moral and immoral decisions in subsequent consumption decisions) or seek security (and repeat their moral or immoral behavior).

Due to their desire to accomplish security goals, people with a strong prevention focus (cf. strongly promotion-focused people) assign more weight to the negative consequences of deviating from the security of the status quo (Chernev, 2004; Scholer, Zou, Fujita, Stroessner, \& Higgins, 2010), such that they are inclined toward stability and conservative strategies (Crowe \& Higgins, 1997; Higgins, 1998; Liberman, Idson, Camacho, \& Higgins, 1999; Zhou \& Pham, 2004). In terms of sequential moral consumption behavior, the prior decisions of prevention- 
focused people constitute the status quo and serve as a heuristic for subsequent decision making (Chernev, 2004; Scholer et al., 2010; Zhang et al., 2014). A moral decision increases the relative importance of morality goals and leads to more moral subsequent consumption behavior.

Following the same line of thought, immoral decisions by prevention-focused people highlight their self-interests, and the immoral decision constitutes the status quo to maintain in subsequent choices. Even immoral decisions can result in a higher willingness to maintain that status quo, constituted by prior behavior, leading to a repetition of immoral decisions.

This reasoning receives support from Zhang, Higgins, and Chen (2011), who show that people with a strong prevention focus copy even the behavior of a role model with whom they have been unsatisfied, to maintain their status quo. Wu and Kao (2011) find that such consumers seek less variety than promotion-focused consumers; in turn, less variety seeking is positively associated with repetitive behavior in sequential moral decisions (Huber et al., 2008). In showing that prevention-focused people are motivated and inclined to repeat both their prior moral (e.g., telling the truth) and immoral (e.g., cheating, hiding information) behavior, Zhang et al. (2014) critically identify what they call the prevention-repetition effect. In accordance with their findings and prior reasoning, we expect the prevention-repetition effect to arise for moral consumption decisions too.

H1: Among prevention-focused consumers, prior (a) moral consumption decisions lead to more moral behavior in subsequent consumption decisions, and (b) immoral decisions lead to more immoral subsequent consumption behavior.

In contrast, consumers with a strong promotion focus pursue progress, positive outcomes, and advancement toward a desired end state (Higgins, 1997, 1998; Semin, Higgins, de Montes, Estourget, \& Valencia, 2005). They are motivated to do whatever it takes to make progress from a status quo to a new, better state; they do not attach value to the status quo but instead value 
advancement away from the current state toward a desired end state (Scholer et al., 2010). Goal progress, defined as how much advancement they perceive that they have made toward achieving an objective, serves as a signal to guide promotion-focused consumers' self-regulative decisions (Salerno, Laran, \& Janiszewski, 2015; Zou, Scholer, \& Higgins, 2014). After some advancement, their sufficient goal progress signals that they can decrease their efforts and shift their focus to other goals (Carver, 2003; Fishbach \& Dhar, 2005; Fishbach, Zhang, \& Koo, 2009). Their prior moral decisions constitute progress toward the goal of developing a self-image of being a moral person; this progress licenses less moral decisions and a greater focus on one's self-interests subsequently (Huber et al., 2008; Joosten et al., 2014; Khan \& Dhar, 2006; Zhong et al., 2009). However, this licensing mechanism applies only if the second decision is morally ambiguous enough to avoid an attribution of immorality to oneself (e.g., choosing not to donate money to a particular charity). Unequivocally immoral behavior, such as cheating or lying, cannot be licensed by prior moral actions (see the subsequent development of $\mathrm{H} 3$ and H4). Rather, the prior immoral decisions of promotion-focused consumers satisfy their self-interested goals and do not constitute progress toward the goal of a moral self-image, signaling the need for them to intensify their efforts (Carver \& Scheier, 2001; Fishbach et al., 2009; Zou et al., 2014). They thus are motivated to compensate for prior wrongdoings with subsequent moral consumption decisions.

This reasoning is in line with prevalent literature suggesting that a stronger promotion focus is associated with greater deviation from the status quo, more openness to change, and greater risk seeking (Chernev, 2004; Liberman et al., 1999; Zhou \& Pham, 2004). A stronger outcomebased mindset also is associated with balance across sequential decisions (Cornelissen, Bashshur, Rode, \& Le Menestrel, 2013). Balancing conflicting goals occurs when people are motivated to seek variety (Fishbach \& Dhar, 2005; Huber et al., 2008), such that variety-seeking behavior is more pronounced among promotion-focused people (Wu \& Kao, 2011). We expect consumers 
with a strong promotion focus to balance their subsequent moral consumption decisions and exhibit more immoral consumption behavior after prior moral consumption decisions (moral licensing) but act more morally after more immoral consumption (moral cleansing).

H2: For promotion-focused consumers, prior (a) moral consumption decisions lead to more immoral behavior in subsequent consumption decisions, but (b) immoral decisions lead to more moral subsequent consumption behavior.

\section{Moral ambiguity of the target behavior}

Moral decision-making situations differ in their moral ambiguity, that is, the degree to which decisions have a clearly moral or immoral bent (Mullen \& Monin, 2016). In situations with low moral ambiguity, the decision maker can choose between an unequivocally moral alternative and a blatant moral transgression - for example, between being honest or cheating. In contrast, decision situations with high moral ambiguity are characterized by some lack of certainty about whether certain behaviors are morally right or wrong, such as denying a bank loan to a gay couple (Krumm \& Corning, 2008).

For prevention-focused consumers, what matters most is maintaining the security of the status quo. The morality of the past behavior (i.e., previous moral decision) determines this status quo and serves as a heuristic for subsequent decision making (Chernev, 2004; Scholer et al., 2010; Zhang et al., 2014). In other words, prevention-focused people rely on their initial behavior as the reference point for subsequent decisions. The ambiguity of the target behavior is not relevant for the decision; these prevention-focused people are willing to "do whatever is necessary to return to the previous status quo" (Scholer et al., 2010, p. 217). Thus Zhang et al. (2014) demonstrate that prevention-focused people repeat their prior moral and immoral decisions, even in situations marked by clear moral transgressions such as lying or cheating. 
Therefore, we expect prevention-focused consumers to repeat both prior moral and immoral decisions subsequently, in situations with either high or low moral ambiguity.

However, moral ambiguity is central to the process of moral rationalization. People are able to interpret their immoral behavior to establish a perception of that behavior as acceptable, neutral, or even moral in some cases. This reinterpretation of immoral behavior reflects the person's ability to provide alternative explanations (Brown et al., 2011). Especially in morally ambiguous situations, people can find alternative explanations to deny immoral motivations, causes, or actions and thus give them excuses for not living up to their own ethical standards (Mullen \& Monin, 2016). For example, people who are not willing to donate money to a charity may explain their unwillingness by claiming they want to give to another charitable cause at some later point. This rationalization helps promotion-focused consumers uphold their moral self-perception, despite acting immorally, as well as give in to the temptation of acting immorally after prior moral decisions to advance toward self-interested goals (Mullen \& Monin, 2016).

If the first decision is immoral, a subsequent decision with high moral ambiguity provides an easy way of cleansing prior wrongdoings and making progress toward the goal of being a moral person. Therefore, promotion-focused consumers take this chance and act more morally after prior immoral decisions when the target behavior is highly morally ambiguous. If the second decision is unambiguously moral or immoral though, the moral option constitutes the dominant choice for promotion-focused consumers, due to its better relation of gains and losses relative to the immoral option. That is, promotion-focused consumers strive for gains and to capture opportunities (Zhou \& Pham, 2004), so they naturally gravitate toward the moral option, regardless of their prior behavior. The moral ambiguity of the target behavior (low vs. high ambiguity) therefore should be irrelevant for the moral self-regulation of prevention-focused consumers but highly relevant to the self-regulative processes of promotion-focused people. We 
expect the moral balancing effect of promotion-focused consumers to disappear for target behaviors with low moral ambiguity, which would provide a compelling explanation for variance in promotion-related research findings (Zhang et al., 2014).

H3: When the target behavior has high moral ambiguity, (a) prevention-focused consumers repeat their prior moral (immoral) decisions, and (b) promotion-focused consumers balance their prior moral (immoral) decisions with subsequent more immoral (moral) consumption behavior.

H4: When the target behavior has low moral ambiguity, (a) prevention-focused consumers repeat their moral (immoral) decisions, and (b) promotion-focused consumers refrain from balancing their moral consumption behavior.

\section{Status quo maintenance and goal progress}

As outlined, prevention-focused consumers repeat both prior moral and immoral decisions. In line with Zhang et al. (2014), we posit that this repetitive behavior is motivated by a desire to maintain the status quo established by past behavior, that is, a motivation not to deviate from prior decisions for security needs and to repeat the moral stance reflected by past behavior (Chernev, 2004; Scholer et al., 2010; Zhang et al., 2014). We therefore test whether the motivation to maintain the status quo mediates the prevention-repetition effect. Specifically, we expect a motivation to maintain the status quo to mediate the influence of both prior moral and immoral consumption behavior on subsequent decisions by prevention-focused consumers.

H5: Prevention-focused consumers are motivated to maintain the status quo after moral (immoral) consumption decisions, which results in more moral (immoral) consumption behavior subsequently.

For consumers with a strong promotion focus, and in line with our reasoning leading to H2, the influence of their prior moral and immoral consumption behavior on subsequent decisions 
may be mediated by perceived progress toward the goal of acting morally. After prior moral decisions, perceived goal progress signals that the goal of acting morally has been sufficiently satisfied, which permits less moral behavior subsequently (Carver, 2003; Fishbach \& Dhar, 2005). Immoral decisions entail a perceived lack of progress toward the goal of acting morally though, resulting in more moral subsequent consumption decisions (Carver \& Scheier, 2001; Fishbach et al., 2009; Zou et al., 2014).

H6: For promotion-focused consumers, a prior moral (immoral) consumption decision positively (negatively) affects perceived progress toward the goal of acting morally, which results in less (more) moral consumption behavior subsequently.

\section{Overview of experimental studies}

We report on four experimental studies to test the effect of a consumer's regulatory focus on his or her moral self-regulation (Table 1). Study 1 shows that consumers with a situationally induced prevention focus repeat their past consumption decisions, but consumers with a situationally induced promotion focus regulate their moral consumption behavior through licensing and cleansing. Study 2 replicates the findings from Study 1 in a different consumption context. Study 3 sheds light on the moderating role of the moral ambiguity of the target behavior, that is, whether the second decision is clearly or ambiguously moral or immoral. For target behavior that is clearly moral or immoral, prevention-focused consumers still repeat their prior moral and immoral decisions, but promotion-focused consumers no longer regulate their moral consumption behavior through licensing and cleansing. Finally, in Study 4, we elaborate on the mechanisms underlying prevention-focused consumers' moral consistency and promotionfocused consumers' moral balancing by testing the mediating roles of motivation to maintain the status quo and perceived goal progress. 


\section{Study 1: Effect of regulatory focus on consumers' moral self-regulation}

\section{Design and procedure}

To test our predictions that a consumers' regulatory focus influences moral self-regulatory consumption behavior, we manipulated the morality of the first decision that the Study 1 participants saw, as well as the induced regulatory focus. Thus, this experiment used a 3 (first decision: moral vs. immoral vs. control) $\times 2$ (regulatory focus: prevention vs. promotion) between-subjects design.

After excluding participants who made mistakes in completing the tasks (see the Methodological Details Appendix [MDA]), the final convenience sample consisted of 182 students and employees of a major German university $\left(50.5 \%\right.$ male; $M_{\text {age }}=26.54$ years, $S D_{\text {age }}=$ 10.61 years), recruited to participate in a laboratory experiment. Participants in the control condition completed an unrelated scrambled sentence task. Comparisons of the outcomes in the moral and immoral conditions against this control group are important to differentiate positive from negative consistency and licensing from cleansing behavior (Mullen \& Monin, 2016).

\section{Measures}

Dependent variable. We used a scale that assesses intentions to purchase green versus conventional groceries as a measure of the morality of the subsequent consumption decision; buying green products allows consumers to express their high ethical standards and social responsibility (Mazar \& Zhong, 2010). In particular, we chose organic and conventional coffee, considering the relevance of this product category to consumers (United States Department of Agriculture, 2016). Participants received short product descriptions that differed in one feature:

One coffee was labeled organic, but we omitted this detail for the conventional coffee. Furthermore, the indicated price of the organic coffee was one-third higher than that of the conventional coffee (for equivalent package sizes). Participants indicated their relative preference 
for organic versus conventional coffee on a 7-point scale $(1=$ most likely to buy the premium coffee and $7=$ most likely to buy the organic premium coffee). The MDA provides details about the materials and scales we used.

Regulatory focus. We used the manipulation developed by Freitas and Higgins (2002) to induce a prevention or promotion focus, as has been applied effectively in many other studies (e.g., Kirmani \& Zhu, 2007; Yoon, Sarial-Abi, \& Gürhan-Canli, 2012). In the prevention focus condition, participants described two of their duties and obligations and wrote a short paragraph about them. In the promotion focus condition, we asked participants to think about their current hopes and aspirations and write a short paragraph about two of them. In line with prior research (e.g., Yoon et al., 2012), we also included four questions to check the adequacy of the regulatory focus manipulation $(1=$ strongly disagree and 7 = strongly agree $)$ : "My major goal right now is to achieve my ambitions," "I am anxious that I will fall short of my responsibilities and obligations," "I am more oriented toward preventing losses than I am toward achieving gains," and "I frequently imagine how I will achieve my hopes and aspirations" (adapted from Lockwood, Jordan, \& Kunda, 2002). We averaged the first and last items for an overall promotion focus score (composite reliability $[\mathrm{CR}]=.69$ ); the aggregation of items 2 and 3 measured prevention focus $(\mathrm{CR}=.67)$.

Morality of the first decision. We manipulated the morality of the first decision using a moral behavior recall task adapted from Conway and Peetz (2012). Participants in the moral recall condition were asked to remember a situation, dating back less than one year, in which they helped someone without any reward or were caring or kind without pursuing their own selfinterests. We also suggested that the situation could have involved being loyal or generous when they could have been selfish. In the immoral recall conditions, participants remembered situations in which they were mean or unfriendly without any particular reason, such as when they acted 
disloyally or selfishly. Next, the participants had to write a short paragraph about the situation they remembered. In the control condition, participants executed an unrelated scrambled sentence task. We checked for the success of the manipulation of the morality of the first decision with four items from Khan and Dhar (2006): "In the described situation, I was compassionate/sympathetic/warm/helpful" (7-point scale, $1=$ strongly disagree and 7 = strongly agree; $\mathrm{CR}=.92)$.

\section{Results}

Manipulation checks. To check if regulatory focus was successfully manipulated, we conducted two two-way analyses of variance (ANOVA), with the regulatory focus manipulation checks as the dependent variables and regulatory focus and the morality of the first decision as the independent variables. As expected, participants in the prevention focus condition scored higher on the prevention focus manipulation check than those in the promotion focus condition $\left(M_{\text {prevention }}=4.06, M_{\text {promotion }}=3.47 ; F(1,176)=8.17, p<.01\right)$. Furthermore, we found a significant main effect of regulatory focus on the promotion focus measure, such that participants in the promotion focus condition showed a stronger promotion focus than those in the prevention focus condition $\left(M_{\text {promotion }}=5.77, M_{\text {prevention }}=5.20 ; F(1,176)=11.72, p<.001\right)$. No other main or interaction effects were significant in the regulatory focus manipulation checks.

In another two-way ANOVA, the manipulation check measure of the first decision's morality was the dependent variable, and the morality of the first decision and regulatory focus were independent variables. As intended, we found a significant main effect of the morality of the first decision but no other statistically significant main or interaction effects. Participants in the moral behavior condition rated the perceived morality of the first decision higher than did participants in the control condition $\left(F(1,176)=159.48, p<.001 ; M_{\text {moral }}=5.77, M_{\text {control }}=4.25\right.$, $\left.p_{\text {moral } / \text { control }}<.001\right)$. The immoral behavior condition was assessed as less moral than the control 
condition $\left(M_{\text {immoral }}=2.39, M_{\text {control }}=4.25, p_{\text {immoral } / \text { control }}<.001\right)$. These results confirm the success of the manipulation.

Hypotheses testing. To examine $\mathrm{H} 1$ and $\mathrm{H} 2$, we conducted a two-way ANOVA with the relative preference for the organic coffee as the dependent variable and regulatory focus and the morality of the first decision as independent variables. The main effects of the morality of the first decision $(F(2,176)=.06, p>.05)$ and regulatory focus $(F(1,176)=.08, p>.05)$ were not significant. However, the ANOVA revealed the predicted two-way interaction between the morality of the first decision and regulatory focus $(F(2,176)=28.05, p<.001)$, as shown in Figure 1. To scrutinize this interaction, we analyzed the effect of the first decision on the relative preference for organic coffee among prevention- and promotion-focused participants separately. In support of both $\mathrm{H} 1 \mathrm{a}$ and $\mathrm{H} 1 \mathrm{~b}$, in the prevention-focused condition, relative preference for the organic coffee was higher among participants who previously recalled moral behavior $(F(2,92)=$ $18.83, p<.001 ; M_{\text {moral }}=5.24, M_{\text {control }}=4.13, p_{\text {moral } / \text { control }}<.05$, Cohen's d= .67). Participants with an induced prevention focus in the immoral behavior recall condition expressed a lower relative preference for organic coffee than those in the control condition $\left(M_{\text {immoral }}=2.65, M_{\text {control }}=4.13\right.$, $p_{\text {immoral } / \text { control }}<.001, \mathrm{~d}=.81$ ). Also consistent with $\mathrm{H} 2 \mathrm{a}$ and $\mathrm{H} 2 \mathrm{~b}$, in the promotion focus condition, participants exhibited balancing behavior: After recalling moral behavior, their relative preference for organic coffee was lower than in the control condition $(F(2,84)=10.64, p<.001$; $\left.M_{\text {moral }}=2.85 ; M_{\text {control }}=4.09, p_{\text {moral } / \text { control }}<.05, \mathrm{~d}=.60\right)$. Promotion-focused participants who recalled more immoral behavior instead had a higher relative preference for organic coffee compared with the control condition $\left(M_{\text {immoral }}=5.33, M_{\text {control }}=4.09, p_{\text {immoral } / \text { control }}<.05, \mathrm{~d}=.60\right)$.

\section{Discussion}

Study 1 provides support for our reasoning that consumers' (situationally induced) regulatory focus influences whether they regulate or repeat their moral consumption decisions. 
For prevention-focused consumers, our results are consistent with findings by Zhang et al. (2014): An induced prevention focus causes consumers to repeat their past behavior, irrespective of the morality of the decision. Thus, the prevention-repetition effect applies to moral consumption too. Promotion-focused participants who previously recalled moral decisions exhibited licensing behavioral patterns, but participants in the promotion focus condition who remembered past immoral decisions instead tried to "clean up" their behavior with more moral behavior subsequently. Whereas an induced promotion focus leads to moral licensing and moral cleansing patterns in consumption domains in our study, Zhang et al. (2014) found no effect of promotion focus on sequential moral behavior in their psychology research. The inconsistency in these findings prompted us to replicate our results in another consumption context in Study 2.

Study 2: Replicating the effect of regulatory focus on consumers' moral self-regulation

\section{Design and procedure}

In Study 2, we examine if the effects from Study 1 replicate in another consumption situation, namely, whether to keep or donate a reward paid to a customer for helping a firm acquire new customers. By manipulating the morality of the first decision and consumers' regulatory focus, we devised a 3 (first decision: moral vs. immoral vs. control) $\times 2$ (regulatory focus: prevention vs. promotion) between-subjects design. A total of 179 students and university employees of a major German university were recruited for the laboratory experiment, through random approach tactics on campus. We excluded 3 participants who did not execute the writing task correctly, resulting in a final sample of 176 participants $\left(39.80 \%\right.$ male; $M_{\text {age }}=26.04$ years, $S D_{\text {age }}=8.93$ years). Participants did not receive any monetary compensation but had the chance to take part in a raffle, as detailed subsequently. 


\section{Measures}

Dependent variable. The choice in the moral trade-off was the dependent measure. Participants had to imagine being customers of the mobile phone company "Now Mobile," who could receive a reward of $€ 15(\sim \$ 17.50)$ for recruiting a friend as a new customer through a referral program. They had a choice between keeping the reward for themselves or donating the money to a fictitious charity, "Against Hunger," which we described in the instrument. The dichotomous dependent variable was $0=$ keep the reward and $1=$ donate the reward.

Regulatory focus. The regulatory focus manipulation and manipulation checks were the same as in Study $1\left(\mathrm{CR}_{\text {prevention }}=.60 ; \mathrm{CR}_{\text {promotion }}=.61\right)$.

Morality of the first decision. Following Mazar and Zhong (2010), we manipulated the first decision by letting participants choose from nine convenience goods (e.g., coffee, potato chips, shampoo) that they would like to buy. In the more moral condition, participants were shown seven green and two conventional convenience goods; in the more immoral condition, seven conventional and two green convenience goods appeared. Participants then chose products to reach a maximum total value of $€ 20(\sim \$ 23.50$; each product ranged in price between $€ 2$ and $€ 5)$ and also were told that they could participate in a raffle in which one of every 25 participants would be chosen to receive the selected products, thereby incentivizing them to choose as many products as possible. Participants in the moral condition ( 7 green and 2 conventional alternatives) chose more green than conventional products; participants in the immoral condition ( 7 conventional and 2 green alternatives) ended up selecting more conventional than green products. In the moral condition, on average, participants selected 4.07 green products and .60 conventional products. In the immoral condition, they chose an average of .88 conventional and 3.78 green products. In line with Mazar and Zhong (2010) and Susewind and Hoelzl (2014), we kept the prices the same for the green and conventional alternatives, such that choosing the more moral 
alternative no longer requires self-sacrifice. In turn, opting for conventional products in this situation should be interpreted as even more immoral than if self-sacrifice were necessary to act morally. Participants in the control condition completed the same unrelated scrambled sentence task as in Study 1. The test of the effectiveness of the manipulation used three items adapted from Mazar and Zhong (2010): "With my product choice I acted socially responsibly," "My product choice was ethical," and "With my product choice I acted altruistically" $(\mathrm{CR}=.80)$. The items were assessed on a 7-point scale $(1=$ strongly disagree and $7=$ strongly agree $)$.

\section{Results}

Manipulation checks. To determine if regulatory focus was manipulated successfully, we conducted two two-way ANOVAs, with the regulatory focus manipulation checks as the dependent variables and regulatory focus and the morality of the first decision as independent variables. As expected, the prevention focus manipulation resulted in a higher prevention focus score than the promotion focus manipulation $\left(M_{\text {prevention }}=4.28, M_{\text {promotion }}=3.44 ; F(1,170)=\right.$ $16.96, p<.001)$. Participants in the promotion focus condition also scored higher on the promotion focus measure than participants in the prevention focus condition $\left(M_{\text {promotion }}=4.27\right.$, $\left.M_{\text {prevention }}=3.51 ; F(1,170)=14.40, p<.001\right)$. The ANOVAs did not yield any other statistically significant main or interaction effects.

Another two-way ANOVA with the morality manipulation check as the dependent variable and the morality of the first decision and regulatory focus as the independent variables yielded a significant main effect of the morality of the first decision; none of the other main or interaction effects were statistically significant. In support of our manipulation, the cell means revealed that participants who chose from seven green and two conventional convenience goods rated the first decision as more moral than participants in the control condition $(F(2,170)=14.97, p<.001)$; $\left.M_{\text {moral }}=4.51, M_{\text {control }}=3.91, p_{\text {moral } / \text { control }}<.001\right)$. Participants who were exposed to seven 
conventional and two green convenience goods rated their decision as less moral than in the control condition $\left(M_{\text {immoral }}=3.24, M_{\text {control }}=3.91, p_{\text {immoral } / \text { control }}<.05\right)$.

Hypotheses testing. To replicate the findings for $\mathrm{H} 1$ and $\mathrm{H} 2$, we conducted a binary logistic regression, with the choice between keeping or donating the reward as the dependent variable and the morality of the first decision, regulatory focus, and their two-way interaction as independent variables (see Table 2 and Figure 2). The morality of the first decision had a significant main effect on donation probability (Wald $\chi^{2}(2)=15.92, p<.001$ ), but regulatory focus did not yield a main effect $\left(b=-.25\right.$, Wald $\left.\chi^{2}(1)=.24, p>.05\right)$.

Notably, the two-way interaction between the morality of the first decision and regulatory focus had a significant effect on donation probability (Wald $\chi^{2}(2)=31.24, p<.001$ ). To clarify this interaction, we analyzed the simple slopes of regulatory focus in each morality condition, which reveals a repetition of the effects we established in Study 1: Consumers with an induced prevention focus were more willing to donate the reward after having selected more green convenience goods than those in the control condition $\left(b=1.20\right.$, Wald $\left.\chi^{2}(1)=3.83, p=.05\right)$. After choosing more conventional convenience goods, prevention-focused participants were less willing to donate the reward than participants in the control condition $\left(b=-1.33\right.$, Wald $\chi^{2}(1)=$ $5.90, p<.05)$. Promotion-focused participants indicated a higher probability of donating to the charity after having chosen from more conventional convenience goods, compared with promotion-focused participants who completed a neutral filler task $\left(b=1.27\right.$, Wald $\chi^{2}(1)=4.66$, $p<.05)$. After selecting more green convenience goods, participants in the promotion focus condition showed a lower donation likelihood than participants in the control condition $(b=-$ 1.21, Wald $\left.\chi^{2}(1)=4.51, p<.05\right)$. 


\section{Discussion}

Study 2 lends further support to the robustness of our Study 1 findings. We show that the prevention-repetition effect proposed by Zhang et al. (2014) replicates in another consumption situation (i.e., donating a reward received for making a successful referral). Whereas Zhang et al. (2014) found no effects of prior moral decisions on subsequent behavior among promotionfocused people, our study corroborates that, in consumer behavior settings, a higher promotion focus causes consumers to balance prior and subsequent moral consumption decisions. In Study 3, we seek to explain the divergence of our results from those of Zhang et al. (2014) by analyzing a contingency of the promotion effect, namely, the moral ambiguity of the target behavior (i.e., second decision).

\section{Study 3: Moral ambiguity of the target behavior}

\section{Design and procedure}

In Study 3, we manipulated consumers' regulatory focus, the morality of the first decision, and the moral ambiguity of the target behavior, with a 3 (first decision: moral vs. immoral vs. control) $\times 2$ (regulatory focus: prevention vs. promotion) $\times 2$ (moral ambiguity of target behavior: low vs. high) between-subjects design. After excluding 4 participants (see the MDA), the final convenience sample consisted of 369 students and staff from a large German university (42\% male; $M_{\text {age }}=22.98$ years, $S D_{\text {age }}=3.37$ years $)$. The experiment consisted of three reportedly unrelated parts of a study. Participants were incentivized by a chance to take part in a raffle.

\section{Measures}

Dependent variable. A scenario with a service mistake in the customer's favor served as the dependent variable. More precisely, we described a restaurant scenario, in which consumers received a bill with missing items (see the MDA for further details). Participants were told that they recognized the mistake, then indicated whether they would point out the mistake to the 
waiter on a 7 -point scale $(1=$ most likely to not point out the mistake and $7=$ most likely to point out the mistake).

Moral ambiguity of the target behavior. For the high moral ambiguity manipulation, we noted that the participant chose the restaurant's dish of the day, which had been listed on a blackboard near the restaurant entrance. When checking the bill, the guest noticed a lower price than what he or she believed had been written on the blackboard. It is an ambiguous situation, because multiple explanations could exist; for example, the guest may decide to not point out the mistake because he or she is not entirely sure to have remembered the price on the blackboard correctly. Thus, the negative behavior can be viewed in a more favorable light, suggesting the situation creates more attributional ambiguity (Merritt et al., 2010; Mullen \& Monin, 2016). In the low ambiguity condition, participants instead read that the dish was completely omitted from the bill. In this situation, not pointing out the mistake reflects less ambiguous moral behavior; there is no alternative possible explanation (i.e., the consumer knows full well his or her behavior is a moral transgression). To check this manipulation, we asked participants to use three 7-point bipolar items and indicate whether failing to point out the mistake is "unambiguously immoralambiguously immoral," "certainly immoral-not really immoral," or "in either case immoral-not in every case immoral" $(C R=.93)$ (adapted from Nordholm, 1975; Okimoto \& Wenzel, 2011). A pretest with 44 graduate students of a major German university $\left(62.20 \%\right.$ male; $M_{\text {age }}=$ 23.11 years, $\left.S D_{\text {age }}=3.04\right)$ confirmed that the scenarios were perceived as situations marked by higher or lower moral ambiguity. Not pointing out that the dish appeared on the bill with a lower price was perceived as more ambiguously immoral, less certainly immoral, and less definitely immoral $\left(M_{\text {high }}=4.18\right)$ than not pointing out that the dish was completely missing $\left(M_{\text {low }}=2.73\right.$; $t(43)=-2.93, p<.01)$. Thus, our manipulation of moral ambiguity was successful. 
Regulatory focus. We applied the same regulatory focus manipulation and manipulation checks as in the Studies 1 and $2\left(\mathrm{CR}_{\text {promotion }}=.82 ; \mathrm{CR}_{\text {prevention }}=.60\right)$.

Morality of the first decision. To manipulate participants' first decision, we applied the scenario with nine different convenience goods from Study 2 to a clothing context. Participants were instructed to make purchase decisions, using vouchers ranging in value from $€ 2$ to $€ 5$. They chose from a set of nine vouchers redeemable for green versus conventional clothes (e.g., t-shirts, jeans, underwear). In the moral (immoral) condition, the set contained 7 vouchers for green (conventional) clothes and 2 for conventional (green) clothes. The sets did not differ in their prices or ratio of green and conventional alternatives. In the moral condition, participants selected an average of 4.49 green clothing vouchers and .55 conventional vouchers. In the immoral condition, they chose an average of 4 conventional and 1.09 green clothing vouchers. They also had an opportunity to take part in a raffle and actually receive the chosen vouchers. We used the same manipulation check as in Study $2(\mathrm{CR}=.80)$. Participants in the control condition filled in an unrelated scrambled sentence task (as in Studies 1 and 2).

\section{Results}

Manipulation checks. Two three-way ANOVAs with the promotion/prevention manipulation check measures as the dependent variables and morality of the first decision, regulatory focus, and moral ambiguity as independent variables showed that the prevention focus manipulation check measure was higher for participants in the prevention than in the promotion condition $\left(M_{\text {prevention }}=3.90, M_{\text {promotion }}=3.28 ; F(1,357)=15.18, p<.001\right)$. Participants in the promotion focus condition also scored higher on the promotion focus items than those in the prevention focus condition $\left(M_{\text {promotion }}=5.69, M_{\text {prevention }}=5.03 ; F(1,357)=30.33, p<.001\right)$.

We conducted another three-way ANOVA with the morality manipulation check as the dependent variable and the morality of the first decision, regulatory focus, and moral ambiguity 
as independent variables. Participants in the moral condition rated the first decision as more moral than participants in the control condition $\left(F(2,357)=20.25, p<.001 ; M_{\text {moral }}=4.45, M_{\text {control }}\right.$ $\left.=3.87, p_{\text {moral } / \text { control }}<.01\right)$. Furthermore, the rating of the immoral condition was lower than in the control group $\left(M_{\text {moral }}=3.43, M_{\text {control }}=3.92, p_{\text {immoral } / \text { control }}<.05\right)$. As expected, we did not find other statistically significant main or interaction effects.

To check the manipulation of moral ambiguity, we conducted a three-way ANOVA with the manipulation check as the dependent variable and moral ambiguity, regulatory focus, and the morality of the first decision as independent variables. In support of our manipulation, participants in the high ambiguity condition perceived not pointing out the mistake as more ambiguously immoral than those in the low ambiguity condition $\left(M_{\text {low }}=2.78, M_{\text {high }}=4.02 ; F(1\right.$, $357)=49.42, p<.001)$. There were no other statistically significant main or interaction effects.

Hypotheses testing. To test $\mathrm{H} 3$ and $\mathrm{H} 4$, we conducted a three-way ANOVA with the intention to point out the service mistake as the dependent variable and regulatory focus, the morality of the first decision, and moral ambiguity as independent variables. The results revealed that ambiguity decreased intentions to point out the mistake $(F(1,357)=36.98, p<.001)$. Moreover, the ANOVA yielded a significant three-way interaction among regulatory focus, the morality of the first decision, and moral ambiguity $(F(2,357)=4.47, p<.05)$. By examining the effect separately for the high and low ambiguity conditions, we can confirm H3a and H3b as well as $\mathrm{H} 4 \mathrm{a}$ and $\mathrm{H} 4 \mathrm{~b}$. As the results in Figure 3 show, for situations with more moral ambiguity, we replicate our findings from Studies 1 and 2; participants with a stronger prevention focus repeated their prior behavior and expressed a higher willingness to point out the service mistake after selecting green clothes, but their intentions to clear up the error were lower when they previously chose conventional clothes $\left(F(2,87)=11.21, p<.001 ; M_{\text {moral }}=5.10, M_{\text {control }}=3.97, M_{\text {immoral }}=\right.$ $2.82 ; p_{\text {moral } / \text { control }}<.05, \mathrm{~d}=.60 ; p_{\text {immoral } / \text { control }}<.05, \mathrm{~d}=.65 ;$ Figure 3 , Panel A). For target behavior 
with greater moral ambiguity, participants with a stronger promotion focus indicated more willingness to point out the error if they previously had chosen conventional clothes, compared with the control group. If a promotion focus prevailed, their stated intentions to clear up the error decreased marginally after selecting green clothes, compared with the control condition $(F(2,89)$ $=10.90, p<.001 ; M_{\text {moral }}=2.64, M_{\text {control }}=3.70, M_{\text {immoral }}=4.93 ; p_{\text {moral } / \text { control }}=.06, \mathrm{~d}=.57$;

$p_{\text {immoral/control }}<.05, \mathrm{~d}=.63$; Figure 3 , Panel A). If instead the moral ambiguity of the target behavior was lower, the prevention-repetition effect persists, but the differences across conditions diminish, compared with the findings in our previous studies $\left(F(2,89)=8.22, p<.01 ; M_{\text {moral }}=\right.$ $5.96, M_{\text {control }}=5.06, M_{\text {immoral }}=4.00 ; p_{\text {moral }} /$ control $=.09, \mathrm{~d}=.54 ; p_{\text {immoral } / \text { control }}=.09, \mathrm{~d}=.56 ;$ Figure 3, Panel B). In addition, for consumers with a strong promotion focus, the balancing effects do not occur. That is, the willingness to point out a service mistake after selecting green or conventional clothes does not differ from the control condition $\left(F(2,92)=.25, p>.05 ; M_{\text {moral }}=\right.$ $5.23, M_{\text {control }}=5.18, M_{\text {immoral }}=4.90 ;$ Figure 3, Panel B) .

\section{Discussion}

This study helps reconcile our findings with extant literature, especially the results provided by Zhang et al. (2014). Study 3 reveals that the promotion-balancing effect does not arise for target behaviors with low moral ambiguity, such as lying or cheating, as were studied by Zhang et al. Thus, it helps explain why prevalent psychology literature has not established a moral selfregulation pattern for people with a strong promotion focus. Instead, the prevention-repetition effect arises for more morally ambiguous target behaviors. In psychology literature, immoral behavior is often described as blatant transgressions, such as lying, cheating or stealing (Cornelissen et al., 2013; Mazar \& Zhong, 2010; Zhang et al., 2014). But in consumption settings, ethicality or morality often is more subtle, such as purchasing green or recycled products (Brinkmann, 2004; Mazar \& Zhong, 2010; Susewind \& Hoelzl, 2014). Consumption decisions, 
and the dependent variables in our studies, offer more moral ambiguity than blatant behaviors such as lying. Therefore, the promotion-balancing and prevention-repetition effects have important implications for understanding morality in the marketplace. Study 4 provides more direct insights into the process by which a promotion or prevention focus exerts different effects on subsequent moral behaviors.

\section{Study 4: The mediating role of status quo maintenance and perceived goal progress}

\section{Design and procedure}

In Study 4, we examine mediators of the prevention-repetition and promotion-balancing effects. We measure consumers' regulatory focus and manipulate the morality of the first decision, thereby devising a one-factorial design with three experimental conditions (first decision: moral vs. immoral vs. control). The sample consisted of 260 students and university employees $\left(52.7 \%\right.$ male; $M_{\mathrm{age}}=22.8$ years, $S D_{\mathrm{age}}=3.35$ years $)$ of a major German university.

\section{Measures}

Dependent variable. In accordance with our dependent variable in Study 1 and morality definition (see "Moral consumption behavior and consumers' moral self-regulation"), we use the intention to purchase eco-friendly versus conventional clothing as the dependent measure.

Participants saw short product descriptions of two sweaters that differed only in that one sweater was made from recycled cotton and polyester, while the other featured conventional cotton and polyester. As in Study 1, the stated price of the eco-friendly sweater was one-third higher than that of the conventional sweater. Participants indicated their relative preference for the ecofriendly sweater on a 7-point scale ( 1 = most likely to buy the sweater from conventional material and $7=$ most likely to buy the sweater from recycled material).

Regulatory focus. To assess consumers' chronic regulatory focus, we used an 18-item scale (Lockwood et al., 2002), with 9 items to assess a chronic prevention (e.g., "In general, I am 
focused on preventing negative events in my life"; $\mathrm{CR}=.81$ ) and 9 items to measure a chronic promotion (e.g., "In general, I am focused on achieving positive outcomes in my life"; CR = .78) goal orientation. Participants responded on 7-point scales $(1=$ strongly disagree and $7=$ strongly agree). Following RFT (Higgins, 1997, 2002), we treat promotion and prevention focus as two separate dimensions. Thus, we averaged the ratings for both subscales and included them as two continuous measures in our analyses.

Morality of the first decision. Following Khan and Dhar (2006), we manipulated the first decision by asking participants to imagine that they received a $€ 500$ tax refund. In the moral condition, participants were told that they decided to donate $€ 100$ of that money to charity. Then, we provided short descriptions of two charity organizations and asked the participants to choose which of the two organizations they would donate the money to. In the immoral condition, participants were told that they decided to donate the money to neither of the organizations but to keep it for themselves. In the control condition, participants chose between two boxes filled with 10 neutral words each, to create a scenario with a morally neutral choice. The manipulation check was the same as the one used in Studies 2 and $3(\mathrm{CR}=.80)$.

Mediators. We measured participants' motivation to maintain the status quo created by the first decision with six items (e.g., "After my prior decision, I would rather stay with my decision than to try something new now"; $C R=.87$; adapted from Yang \& Urminsky, 2015). For participants' perceived progress toward the goal of acting morally, we included six items (e.g., "Due to my prior decision, I feel I've made progress toward my goal of acting morally"; CR = .80; adapted from Cheema \& Bagchi, 2011; Salerno et al., 2015).

\section{Results}

Manipulation checks. A one-way ANOVA with the first decision's morality as the independent variable and the manipulation check as the dependent variable confirmed the success 
of the manipulation of the morality of the first decision. As expected, participants who were told that they had donated part of their tax refund rated their decision as more moral than participants in the control condition $\left(F(2,253)=66.07, p<.001 ; M_{\text {moral }}=4.69, M_{\text {control }}=3.81, p_{\text {moral } / \text { control }}<\right.$ $.001)$. Not donating the money also appeared less moral, relative to the control $\left(M_{\text {immoral }}=2.37\right.$, $\left.M_{\text {control }}=3.81, p_{\text {immoral } / \text { control }}<.001\right)$.

Hypotheses testing. To examine H5, we conducted separate bootstrap dual mediation analyses (Hayes, 2013; model 4; 10,000 samples) for the moral, immoral, and control conditions; prevention focus was the independent variable, motivation to maintain the status quo and perceived goal progress were mediators, and the intention to purchase eco-friendly versus conventional clothing provided the dependent measure (see Table 3). Among participants who donated money (moral condition), the indirect effect of their prevention focus on willingness to purchase the eco-friendly product, through their motivation to maintain the status quo, was positive and significant $($ effect $=.18$; bias-corrected 95\% confidence interval $[\mathrm{CI}]=[.05, .41])$. Perceived goal progress did not mediate this relationship $($ effect $=.04$; bias-corrected $95 \% \mathrm{CI}=[-$ $.09, .22])$. For participants who kept the money for themselves (immoral condition), a stronger prevention focus also exerted an indirect effect on the target behavior, through motivation to maintain the status quo (effect $=-.10$; bias-corrected $95 \% \mathrm{CI}=[-.30,-.007])$. Perceived goal progress again did not mediate the relationship between prevention focus and the dependent variable $($ effect $=-.09$; bias-corrected $95 \% \mathrm{CI}=[-.27, .01])$. Thus, our results support H5.

For H6, we conducted separate dual mediation analyses (Hayes, 2013; model 4; 10,000 samples) for the moral, immoral, and control conditions, with promotion focus as the independent variable but the same mediators and dependent measure (Table 3). In the moral condition, promotion focus exerts a negative indirect effect on willingness to purchase the eco-friendly product, through perceived goal progress $($ effect $=-.18$; bias-corrected $95 \% \mathrm{CI}=[-.44,-.04]$ ) 
Motivation to maintain the status quo does not mediate this relationship (effect = -.05; biascorrected $95 \% \mathrm{CI}=[-.27, .12])$. Perceived goal progress also fully mediates the relationship between a promotion focus and willingness to purchase the eco-friendly sweater in the immoral condition $($ effect $=.29$; bias-corrected $95 \% \mathrm{CI}=[.04, .67])$. Again, in the immoral condition, we find no significant indirect effect through motivation to maintain the status quo (effect $=-.009$; bias-corrected $95 \% \mathrm{CI}=[-.18, .12])$. The results confirm the process described in H6.

\section{Discussion}

This study provides support for the proposed process by which prevention-focused consumers repeat both prior moral and immoral behavior, due to their motivation to maintain the status quo. We thus empirically confirm the mediator proposed (but not tested) by Zhang et al. (2014). Yet promotion-focused consumer behavior is not influenced by a motivation to maintain the status quo but rather by perceived progress toward the goal of acting morally. After moral decisions, promotion-focused consumers perceive progress toward their morality goals, allowing for subsequent transgressions. In contrast, immoral consumption decisions hinder their goal progress, leading to compensatory consumption decisions subsequently.

\section{General discussion}

Consumers' moral decisions in the marketplace do not take place in isolation; they are influenced by past moral decisions. Thus, it is important to understand consumers' moral selfregulation in sequential consumption situations. With four experimental studies, we explore when and why consumers repeat or balance their behavior and accordingly corroborate the preventionrepetition effect, while also revealing a promotion-balancing effect. These results have important implications for consumer theory, especially for the study of consumers' moral self-regulation, as well as potential real-world implications for companies. 


\section{Contributions to theory and practice}

Our results from four laboratory studies show that a consumer's inherent or situationally induced regulatory focus influences whether he or she regulates or repeats moral consumption decisions, which suggests three main theoretical contributions. First, this research reveals that the prevention-repetition effect described in psychology studies (Zhang et al., 2014) exists in general consumption behavior, as well as in specific consumption contexts. We also demonstrate the robustness of the prevention-repetition effect, confirmed for both blatant and for more morally ambiguous behaviors. This extended discussion of the influence of regulatory focus on moral self-regulation patterns, to the domain of consumer behavior, thus contributes theoretically to a better understanding of repetitive behavior in the marketplace. We provide empirical support for the prediction that the prevention-repetition effect stems from prevention-focused consumers' strong motivation to maintain the status quo created by their own prior decisions.

Second, in consumption situations, promotion-focused consumers balance their moral and immoral behavior. Specifically, we show that balancing effects occur only among consumers with a strong promotion focus. We thus contribute to explaining the frequently reported small effect sizes of moral balancing (Blanken et al., 2015). Even within the group of promotionfocused consumers though, moral balancing effects prevail only when the target behaviors are not clearly moral or immoral. Consumption decisions typically involve less clear-cut morality than the unequivocal moral decisions typically studied in psychology research, so our research contributes to an expanded understanding of the dynamics of consumers' moral self-regulation.

Third, we affirm that promotion-focused people balance their consumption decisions and show that perceived progress toward the goal of being a moral person is the motive that underlies the promotion-balancing effect. In so doing, we contribute to a better understanding of moral licensing and moral cleansing effects and the influence of promotion focus on these sequential 
consumption behaviors. Overall, our findings contribute theoretically to a better understanding of morality in the marketplace.

Furthermore, our findings have some interesting practical implications. Companies with substantial information about consumers' past consumption decisions and preferences (e.g., online retailers) might benefit particularly from our insights. If companies want to induce selfregulation, to sway consumers to consider more sustainable alternatives, they might use online product ads to induce a particular regulatory focus. Consumers' regulatory focus can be affected by situational primes (e.g., Lee \& Aaker, 2004). For shoppers who previously consumed moral products (e.g., recycled or cause-related products), a prevention focus will encourage them to make more moral consumption decisions thereafter. Targeting these customers with preventionrelated messages (e.g., highlighting how organic products protect the environment) may strengthen their preference for moral consumption decisions. If they previously consumed less moral options, the ads instead might aim to induce a promotion focus (e.g., promoting green products as a means to improve one's own health), to evoke cleansing behavior (i.e., more moral consumption decisions) subsequently.

Furthermore, companies could reduce licensing effects in consumption decisions by increasing the perceived clarity (i.e., lack of ambiguity) of the moral consumption situation. Following their prior moral consumption behaviors, a company might present shoppers with information or ads emphasizing the importance of consumption decisions for the welfare of others and the environment. The lower perceived ambiguity of the moral consumption decision would reduce promotion-focused consumers' license for moral transgressions, while also allowing prevention-focused consumers to repeat their prior moral decisions.

Charitable organizations also might find these results of benefit. Donors who have been generous in the past could be sent thank you cards telling them, for example, that through their 
donations, they contributed to a moral cause such as preventing the transmission of a certain disease in a developing country. The resulting induced prevention focus should stimulate their repetitive moral behavior. People who have not donated in the past instead could be sent flyers stating that contributions are necessary to improve, for example, education in developing countries; the promotion focus thus induced should lead to more donations subsequently.

\section{Limitations and further research}

To gain a better understanding of the complex processes of moral self-regulation, we examined sequential moral consumption decisions; we do not shed any light on the erosion of moral licensing or cleansing mechanisms over time. The goal progress achieved through moral behavior and the license for subsequent immoral decisions both may diminish over time (Miller \& Effron, 2010). Replications of our studies using longitudinal data would be an important next step to increase the generalizability of the findings. Additional studies showing that promotionfocused consumers behave immorally in a situation that follows moral consumption, but not thereafter, also could strengthen our theoretical reasoning regarding the moral licensing effect.

We analyzed the ambiguity of the target behavior as a contingency effect on the influence of a promotion focus on moral self-regulation. Other boundary conditions also might influence promotion-focused consumers' moral balancing or prevention-focused consumers' consistency patterns, such as the social observability of consumption. That is, licensing effects are more pronounced for public rather than private moral behavior (Kristofferson, White, \& Peloza, 2014), such that private consumption might diminish the promotion-balancing effect, but a preventionrepetition effect might persist even after private initial behavior, due to prevention-focused consumers' motive to maintain the status quo. Studies of the boundary conditions of the prevention-repetition effect also could provide novel insights into how prevention-focused consumers might be prevented from repeating their prior immoral decisions. 
We studied two cognitive mediators of the self-regulatory patterns in moral consumption behavior; further research might test emotions as mediators. Prevalent literature suggests that different emotions arise as a function of the prevailing regulatory focus (e.g., Higgins, Shah, \& Friedman, 1997). Examining these mediators could further improve our understanding of the factors that underlie moral balancing and moral consistency.

We studied different moral consumption contexts, such as purchases of organic food products, which might benefit not only the environment and others (e.g., farmers), but also the decision maker him- or herself (who benefits from healthier food). Further research might study moral decision making in other decision contexts, such as when the welfare of others does not concomitantly increase with the decision-maker's welfare.

Finally, for our four studies, we used experimental laboratory settings. Further studies with consequential choices and behaviors or field studies would help augment the external validity of our findings. We studied moral self-regulation in relation to individual consumption decisions, but consumers with different regulatory foci might not display the same moral self-regulation when making consumption decisions as part of a group (Detert, Treviño, \& Sweitzer, 2008). This issue could be addressed with further experiments that take place in varied consumer decisionmaking contexts. 


\section{References}

Aquino, K., Freeman, D., Reed II, A., Lim, V. K., \& Felps, W. (2009). Testing a social-cognitive model of moral behavior: the interactive influence of situations and moral identity centrality. Journal of Personality and Social Psychology, 97(1), 123-141. doi:

$10.1037 / \mathrm{a} 0015406$

Ariely, D. (2008). Predictably irrational. New York: HarperCollins.

Blanken, I., van de Ven, N., \& Zeelenberg, M. (2015). A meta-analytic review of moral licensing. Personality and Social Psychology Bulletin, 41(4), 540-558. doi:

$10.1177 / 0146167215572134$

Brinkmann, J. (2004). Looking at consumer behavior in a moral perspective. Journal of Business Ethics, 51(2), 129-141. doi: 10.1023

Brown, R. P., Tamborski, M., Wang, X., Barnes, C. D., Mumford, M. D., Connelly, S., \& Devenport, L. D. (2011). Moral credentialing and the rationalization of misconduct. Ethics \& Behavior, 21(1), 1-12. doi: 10.1080/10508422.2011.537566

Carver, C. (2003). Pleasure as a sign you can attend to something else: Placing positive feelings within a general model of affect. Cognition \& Emotion, 17(2), 241-261. doi:

$10.1080 / 02699930302294$

Carver, C. S., \& Scheier, M. F. (2001). On the self-regulation of behavior. Cambridge University Press.

Cheema, A., \& Bagchi, R. (2011). The effect of goal visualization on goal pursuit: Implications for consumers and managers. Journal of Marketing, 75(2), 109-123. doi: 10.1509/jmkg.75.2.109

Chernev, A. (2004). Goal-attribute compatibility in consumer choice. Journal of Consumer Psychology, 14(1), 141-150. doi: 10.1207/s15327663jcp1401\&2_16 
Conway, P., \& Peetz, J. (2012). When does feeling moral actually make you a better person?

Conceptual abstraction moderates whether past moral deeds motivate consistency or compensatory behavior. Personality and Social Psychology Bulletin, 38(7), 907-919. doi: $10.1177 / 0146167212442394$

Cornelissen, G., Bashshur, M. R., Rode, J., \& Le Menestrel, M. (2013). Rules or consequences? The role of ethical mind-sets in moral dynamics. Psychological Science, 24(4), 482-488. doi: $10.1177 / 0956797612457376$

Cornelissen, G., Pandelaere, M., Warlop, L., \& Dewitte, S. (2008). Positive cueing: Promoting sustainable consumer behavior by cueing common environmental behaviors as environmental. International Journal of Research in Marketing, 25(1), 46-55. doi: $10.1177 / 0956797612457376$

Crowe, E., \& Higgins, E. T. (1997). Regulatory focus and strategic inclinations: Promotion and prevention in decision-making. Organizational Behavior and Human Decision Processes, 69(2), 117-132. doi: 10.1006/obhd.1996.2675

Detert, J. R., Treviño, L. K., \& Sweitzer, V. L. (2008). Moral disengagement in ethical decision making: a study of antecedents and outcomes. Journal of Applied Psychology, 93(2), 374391. doi: 10.1037/0021-9010.93.2.374

Eskine, K. J. (2013). Wholesome foods and wholesome morals? Organic foods reduce prosocial behavior and harshen moral judgments. Social Psychological and Personality Science, 4(2), 251-254. doi: 10.1177/1948550612447114

Fishbach, A., \& Dhar, R. (2005). Goals as excuses or guides: The liberating effect of perceived goal progress on choice. Journal of Consumer Research, 32(3), 370-377. doi: $10.1086 / 497548$ 
Fishbach, A., Zhang, Y., \& Koo, M. (2009). The dynamics of self-regulation. European Review of Social Psychology, 20(1), 315-344. doi: 10.1080/10463280903275375

Freitas, A. L., \& Higgins, E. T. (2002). Enjoying goal-directed action: The role of regulatory fit. Psychological Science, 13(1), 1-6. doi: 10.1111/1467-9280.00401

Gawronski, B., \& Strack, F. (2012). Cognitive consistency: A fundamental principle in social cognition. New York: Guilford Press.

Gino, F., Norton, M. I., \& Ariely, D. (2010). The counterfeit self the deceptive costs of faking it. Psychological Science, 21(5), 712-720. doi: 10.1177/0956797610366545

Gneezy, A., Imas, A., Brown, A., Nelson, L. D., \& Norton, M. I. (2012). Paying to be nice: Consistency and costly prosocial behavior. Management Science, 58(1), 179-187. doi: $10.1287 / \mathrm{mnsc} .1110 .1437$

Hayes, A. F. (2013). An introduction to mediation, moderation, and conditional process analysis. New York: The Guilford Press.

Higgins, E. T. (1997). Beyond pleasure and pain. American Psychologist, 52(12), 1280-1300. doi: 10.1037/0003-066X.52.12.1280

Higgins, E. T. (1998). Promotion and prevention: Regulatory focus as a motivational principle. Advances in Experimental Social Psychology, 30, 1-46. doi: 10.1016/S00652601(08)60381-0

Higgins, E. T. (2002). How self-regulation creates distinct values: The case of promotion and prevention decision making. Journal of Consumer Psychology, 12(3), 177-191. doi: 10.1207/S15327663JCP1203_01

Higgins, E. T., Shah, J., \& Friedman, R. (1997). Emotional responses to goal attainment: strength of regulatory focus as moderator. Journal of Personality and Social Psychology, 72(3), 515-525. doi: 10.1037/0022-3514.72.3.515 
Huber, J., Goldsmith, K., \& Mogilner, C. (2008). Reinforcement versus balance response in sequential choice. Marketing Letters, 19(3-4), 229-239. doi: 10.1007/s11002-008-9042-5

Jeong, H. J., \& Koo, D. M. (2015). Volunteering as a mechanism to reduce guilt over purchasing luxury items. Journal of Product \& Brand Management, 24(7), 758-769. doi: 10.1108/JPBM-01-2015-0784

Joosten, A., Van Dijke, M., Van Hiel, A., \& De Cremer, D. (2014). Feel good, do-good!? On consistency and compensation in moral self-regulation. Journal of Business Ethics, 123(1), 71-84. doi: 10.1007/s10551-013-1794-Z

Karmarkar, U. R., \& Bollinger, B. (2015). BYOB: How bringing your own shopping bags leads to treating yourself and the environment. Journal of Marketing, 79(4), 1-15. doi: $10.1509 /$ jm. 13.0228

Khan, U., \& Dhar, R. (2006). Licensing effect in consumer choice. Journal of Marketing Research, 43(2), 259-266. doi: 10.1509/jmkr.43.2.259

Kirmani, A., \& Zhu, R. (2007). Vigilant against manipulation: The effect of regulatory focus on the use of persuasion knowledge. Journal of Marketing Research, 44(4), 688-701. doi: 10.1509/jmkr.44.4.688

Krishna, A. (2011). Can supporting a cause decrease donations and happiness? The cause marketing paradox. Journal of Consumer Psychology, 21(3), 338-345. doi: 10.1016/j.jcps.2011.02.001

Kristofferson, K., White, K., \& Peloza, J. (2014). The nature of slacktivism: How the social observability of an initial act of token support affects subsequent prosocial action. Journal of Consumer Research, 40(6), 1149-1166. doi: 10.1086/674137 
Krumm, A. J., \& Corning, A. F. (2008). Who believes us when we try to conceal our prejudices? The effectiveness of moral credentials with in-groups versus out-groups. Journal of Social Psychology, 148, 689-709. doi: 10.3200/SOCP.148.6.689-710

Lee, A. Y., \& Aaker, J. L. (2004). Bringing the frame into focus: the influence of regulatory fit on processing fluency and persuasion. Journal of Personality and Social Psychology, 86(2), 205-218. doi: 10.1037/0022-3514.86.2.205

Liberman, N., Idson, L. C., Camacho, C. J., \& Higgins, E. T. (1999). Promotion and prevention choices between stability and change. Journal of Personality and Social Psychology, 77(6), 1135-1145. doi: 10.1037/0022-3514.77.6.1135

Lockwood, P., Jordan, C. H., \& Kunda, Z. (2002). Motivation by positive or negative role models: Regulatory focus determines who will best inspire us. Journal of Personality and Social Psychology, 83(4), 854-864. doi: 10.1037/0022-3514.83.4.854

Mazar, N., Amir, O., \& Ariely, D. (2008). The dishonesty of honest people: A theory of selfconcept maintenance. Journal of Marketing Research, 45(6), 633-644. doi: 10.1509/jmkr.45.6.633

Mazar, N., \& Zhong, C. B. (2010). Do green products make us better people? Psychological Science, 21(4), 494-498. doi: 10.1177/0956797610363538

Merritt, A. C., Effron, D. A., \& Monin, B. (2010). Moral self-licensing: When being good frees us to be bad. Social and Personality Psychology Compass, 4(5), 344-357. doi: 10.1111/j.1751-9004.2010.00263.x

Miller, D. T., \& Effron, D. A. (2010). Psychological license: When it is needed and how it functions. Advances in Experimental Social Psychology, 43, 115-155. doi: 10.1016/S00652601(10)43003-8 
Mullen, E., \& Monin, B. (2016). Consistency versus licensing effects of past moral behavior. Annual Review of Psychology, 67(1), 363-385. doi: 10.1146/annurev-psych-010213-115120

Nordholm, L. A. (1975). Effects of group size and stimulus ambiguity on conformity. Journal of Social Psychology, 97(1), 123-130. doi: 10.1080/00224545.1975.9923321

Okimoto, T. G., \& Wenzel, M. (2011). The other side of perspective taking: Transgression ambiguity and victims' revenge against their offender. Social Psychological and Personality Science, 2(4), 373-378. doi: 10.1177/1948550610393032

Sachdeva, S., Iliev, R., \& Medin, D. L. (2009). Sinning saints and saintly sinners the paradox of moral self-regulation. Psychological Science, 20(4), 523-528. doi: 10.1111/j.14679280.2009.02326.x

Salerno, A., Laran, J., \& Janiszewski, C. (2015). Pride and regulatory behavior: The influence of appraisal information and self-regulatory goals. Journal of Consumer Research, 42(3), 499514. doi: $10.1093 /$ jcr/ucv037

Scholer, A. A., Zou, X., Fujita, K., Stroessner, S. J., \& Higgins, E. T. (2010). When risk seeking becomes a motivational necessity. Journal of Personality and Social Psychology, 99(2), 215-231. doi: 10.1037/a0019715

Semin, G. R., Higgins, T., de Montes, L. G., Estourget, Y., \& Valencia, J. F. (2005). Linguistic signatures of regulatory focus: how abstraction fits promotion more than prevention. Journal of Personality and Social Psychology, 89(1), 36-45. doi: 10.1037/00223514.89.1.36

Susewind, M., \& Hoelzl, E. (2014). A matter of perspective: Why past moral behavior can sometimes encourage and other times discourage future moral striving. Journal of Applied Social Psychology, 44(3), 201-209. doi: 10.1111/jasp.12214 
United States Department of Agriculture (2016). Coffee: World markets and trade. Retrieved from http://www.fas.usda.gov/data/coffee-world-markets-and-trade

Wu, P. H., \& Kao, D. T. (2011). Goal orientation and variety seeking behavior: The role of decision task. Journal of Economic Psychology, 32(1), 65-72. doi:

10.1016/j.joep.2010.11.005

Yang, A. X., \& Urminsky, O. (2015). The foresight effect: Local optimism motivates consistency and local pessimism motivates variety. Journal of Consumer Research, 42(3), 361-377. doi: 10.1093/jcr/ucv039

Yoon, Y., Sarial-Abi, G., \& Gürhan-Canli, Z. (2012). Effect of regulatory focus on selective information processing. Journal of Consumer Research, 39(1), 93-110. doi: $10.1086 / 661935$

Zhang, S., Cornwell, J. F., \& Higgins, E. T. (2014). Repeating the past prevention focus motivates repetition, even for unethical decisions. Psychological Science, 25(1), 179-187. doi: $10.1177 / 0956797613502363$

Zhang, S., Higgins, E. T., \& Chen, G. (2011). Managing others like you were managed: how prevention focus motivates copying interpersonal norms. Journal of Personality and Social Psychology, 100(4), 647-663. doi: 10.1037/a0021750

Zhong, C. B., Liljenquist, K. A., \& Cain, D. M. (2009). Moral self-regulation: Licensing and compensation. In D. De Cremer (Eds.), Psychological Perspectives on Ethical Behavior and Decision Making (pp. 75-90). Charlotte, NC: Information Age Publishing.

Zhou, R., \& Pham, M. T. (2004). Promotion and prevention across mental accounts: When financial products dictate consumers' investment goals. Journal of Consumer Research, 31(1), 125-135. doi: 10.1086/383429 
Zou, X., Scholer, A. A., \& Higgins, E. T. (2014). In pursuit of progress: promotion motivation and risk preference in the domain of gains. Journal of Personality and Social Psychology, 106(2), 183-201. doi: 10.1037/a0035391 


\section{Table 1}

Overview of experimental studies.

\begin{tabular}{|c|c|c|c|c|}
\hline & Study 1 & Study 2 & Study 3 & Study 4 \\
\hline Purpose & $\begin{array}{l}\text { Analysis of } \\
\text { influence of } \\
\text { regulatory focus } \\
\text { on moral } \\
\text { balancing and } \\
\text { consistency }\end{array}$ & $\begin{array}{l}\text { Replication of } \\
\text { influence of } \\
\text { regulatory focus } \\
\text { on moral } \\
\text { balancing and } \\
\text { consistency }\end{array}$ & $\begin{array}{l}\text { Study of the moral } \\
\text { ambiguity of the } \\
\text { target behavior as } \\
\text { a boundary } \\
\text { condition for the } \\
\text { influence of } \\
\text { promotion focus } \\
\text { on moral } \\
\text { balancing effect }\end{array}$ & $\begin{array}{l}\text { Study of the } \\
\text { processes } \\
\text { underlying the } \\
\text { differing } \\
\text { influence of } \\
\text { promotion and } \\
\text { prevention focus } \\
\text { on sequential } \\
\text { moral } \\
\text { consumption } \\
\text { decisions }\end{array}$ \\
\hline $\begin{array}{l}\text { Experim } \\
\text { ental } \\
\text { Design }\end{array}$ & $\begin{array}{l}3 \text { (first decision: } \\
\text { moral vs. immoral } \\
\text { vs. control) } \times 2 \\
\text { (regulatory focus: } \\
\text { prevention vs. } \\
\text { promotion) design }\end{array}$ & $\begin{array}{l}3 \text { (first decision: } \\
\text { moral vs. immoral } \\
\text { vs. control) } \times 2 \\
\text { (regulatory focus: } \\
\text { prevention vs. } \\
\text { promotion) design }\end{array}$ & $\begin{array}{l}3 \text { (first decision: } \\
\text { moral vs. immoral } \\
\text { vs. control) } \times 2 \\
\text { (moral ambiguity: } \\
\text { high vs. low) } \times 2 \\
\text { (regulatory focus: } \\
\text { prevention vs. } \\
\text { promotion) design }\end{array}$ & $\begin{array}{l}3 \text { (first decision: } \\
\text { moral vs. } \\
\text { immoral vs. } \\
\text { control) factorial } \\
\text { design, regulatory } \\
\text { focus and } \\
\text { mediators } \\
\text { measured }\end{array}$ \\
\hline $\begin{array}{l}\text { Studied } \\
\text { consump } \\
\text { tion } \\
\text { behavior }\end{array}$ & $\begin{array}{l}\text { - First decision: } \\
\text { recalled moral or } \\
\text { immoral } \\
\text { behavior } \\
\text { - Second decision: } \\
\text { relative } \\
\text { preference for } \\
\text { organic or } \\
\text { conventional } \\
\text { coffee }\end{array}$ & $\begin{array}{l}\text { - First decision: } \\
\text { choice of green } \\
\text { or conventional } \\
\text { convenience } \\
\text { goods } \\
\text { - Second decision: } \\
\text { choice to keep } \\
\text { or donate reward } \\
\text { in a customer } \\
\text { referral program }\end{array}$ & $\begin{array}{l}\text { - First decision: } \\
\text { choice of green } \\
\text { or conventional } \\
\text { clothes } \\
\text { - Second decision: } \\
\text { point out service } \\
\text { mistake }\end{array}$ & $\begin{array}{l}\text { - First decision: } \\
\text { donate to } \\
\text { charity or keep } \\
\text { money for } \\
\text { oneself } \\
\text { - Second } \\
\text { decision: } \\
\text { relative } \\
\text { preference for } \\
\text { sweater made } \\
\text { from recycled } \\
\text { or conventional } \\
\text { materials }\end{array}$ \\
\hline Sample & $\begin{array}{l}\mathrm{n}=182 \\
50.5 \% \text { male } \\
\text { Mean age }=26.54 \\
(\mathrm{SD}=10.61)\end{array}$ & $\begin{array}{l}\mathrm{n}=176 \\
39.80 \% \text { male } \\
\text { Mean age }=26.04 \\
(\mathrm{SD}=8.93)\end{array}$ & $\begin{array}{l}\mathrm{n}=369 \\
42 \% \text { male } \\
\text { Mean age }=22.98 \\
(\mathrm{SD}=3.37)\end{array}$ & $\begin{array}{l}\mathrm{n}=260 \\
52.7 \% \text { male } \\
\text { Mean age }=22.8 \\
(\mathrm{SD}=3.35)\end{array}$ \\
\hline
\end{tabular}




\section{Table 2}

Effect of regulatory focus and morality of the first decision on preference for donating the reward (Study 2).

\begin{tabular}{|c|c|c|c|c|}
\hline \multirow[t]{2}{*}{ Independent Variable } & \multirow{2}{*}{$\begin{array}{r}b \\
(\mathrm{SE})\end{array}$} & \multicolumn{3}{|c|}{ 95\% CI for Odds Ratio } \\
\hline & & LLCI & $\begin{array}{l}\text { Odds } \\
\text { Ratio }\end{array}$ & ULCI \\
\hline Regulatory focus (RF) & $\begin{array}{r}-.25 \\
(.52)\end{array}$ & .27 & .77 & 2.14 \\
\hline Dummy 1 (moral vs. control) & $\begin{array}{r}1.20 * * \\
(.61)\end{array}$ & .99 & 3.32 & 11.05 \\
\hline Dummy 2 (immoral vs. control) & $\begin{array}{r}-1.33^{* *} \\
(.55)\end{array}$ & .08 & .26 & .77 \\
\hline $\mathrm{RF} \times$ Dummy 1 & $\begin{array}{r}-2.41 * * * \\
(.83)\end{array}$ & .01 & .08 & .446 \\
\hline $\mathrm{RF} \times$ Dummy 2 & $\begin{array}{r}2.61 * * * \\
(.80)\end{array}$ & 2.80 & 13.62 & 66.24 \\
\hline
\end{tabular}

Note: $\mathrm{N}=176$. Nagelkerke's $\mathrm{R}^{2}=.26$. For regulatory focus, a value of 0 represents a prevention focus, and 1 represents a promotion focus. The morality of the first decision was dummy coded, such that Dummy 1 compares choosing green convenience goods in the first decision (value 1) with the control condition (value 0), and Dummy 2 compares donation preferences for participants who subsequently chose from conventional convenience goods (value 1) with participants in the control condition (value 0 ). $\mathrm{CI}=$ confidence interval, $\mathrm{LLCI}=$ lower level confidence interval, ULCI = upper level confidence interval, and $\mathrm{SE}=$ standard error.

$* * \quad$ Significant at $p \leq .05$.

$* * *$ Significant at $p \leq .01$. 


\section{Table 3}

Dual mediation analyses (Study 4) for influence of regulatory focus on intention to purchase eco-friendly sweater (ECO) through motivation to maintain status quo (SQ) and perceived goal progress (GP).

\begin{tabular}{|c|c|c|c|c|c|}
\hline Regulatory Focus & Effect (SE) & $\mathrm{t}$ & $p$ & BootLLCI & BootULCI \\
\hline \multicolumn{6}{|l|}{$\begin{array}{l}\text { Prevention Focus } \\
\text { Moral }\end{array}$} \\
\hline Prevention $\rightarrow$ ECO & $.39(.18)$ & 2.07 & .04 & .01 & .76 \\
\hline Prevention $\rightarrow$ SQ $\rightarrow$ ECO & $.18(.08)$ & - & - & .05 & .41 \\
\hline $\begin{array}{l}\text { Prevention } \rightarrow \text { GP } \rightarrow \text { ECO } \\
\text { Immoral }\end{array}$ & $.04(.07)$ & - & - & -.09 & .22 \\
\hline Prevention $\rightarrow$ ECO & $-.52(.18)$ & -2.81 & .00 & -.90 & -.15 \\
\hline Prevention $\rightarrow$ SQ $\rightarrow$ ECO & $-.10(.07)$ & - & - & -.30 & -.007 \\
\hline $\begin{array}{l}\text { Prevention } \rightarrow \mathrm{GP} \rightarrow \mathrm{ECO} \\
\text { Control }\end{array}$ & $-.09(.07)$ & - & - & -.27 & .01 \\
\hline 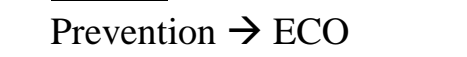 & $-.27(.20)$ & -1.32 & .19 & -.68 & .13 \\
\hline Prevention $\rightarrow$ SQ $\rightarrow$ ECO & $.00(.06)$ & - & - & -.11 & .13 \\
\hline Prevention $\rightarrow$ GP $\rightarrow$ ECO & $-.01(.04)$ & - & - & -.15 & .05 \\
\hline \multicolumn{6}{|l|}{$\begin{array}{l}\text { Promotion Focus } \\
\text { Moral }\end{array}$} \\
\hline 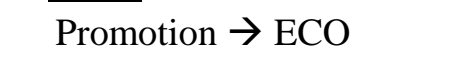 & $-.26(.22)$ & -1.19 & .23 & -.71 & .17 \\
\hline Promotion $\rightarrow \mathrm{SQ} \rightarrow \mathrm{ECO}$ & $-.05(.09)$ & - & - & -.27 & .12 \\
\hline $\begin{array}{l}\text { Promotion } \rightarrow \mathrm{GP} \rightarrow \mathrm{ECO} \\
\underline{\text { Immoral }}\end{array}$ & $-.18(.09)$ & - & - & -.44 & -.04 \\
\hline Promotion $\rightarrow$ ECO & $.13(.25)$ & .51 & .60 & -.38 & .65 \\
\hline Promotion $\rightarrow \mathrm{SQ} \rightarrow \mathrm{ECO}$ & $-.009(.07)$ & - & - & -.18 & .12 \\
\hline $\begin{array}{l}\text { Promotion } \rightarrow \text { GP } \rightarrow \text { ECO } \\
\text { Control }\end{array}$ & $.29(.15)$ & - & - & .04 & .67 \\
\hline Promotion $\rightarrow$ ECO & $-.37(.28)$ & -1.31 & .19 & -.94 & .19 \\
\hline Promotion $\rightarrow \mathrm{SQ} \rightarrow \mathrm{ECO}$ & $-.005(.03)$ & - & - & -.12 & .04 \\
\hline Promotion $\rightarrow$ GP $\rightarrow$ ECO & $-.004(.07)$ & - & - & -.16 & .14 \\
\hline
\end{tabular}




\section{Figures}

Figure 1: Graphical representation of Study 1 results.

Figure 2: Graphical representation of Study 2 results.

Figure 3: Graphical representation of Study 3 results. 
Figure 1: Graphical representation of Study 1 results.

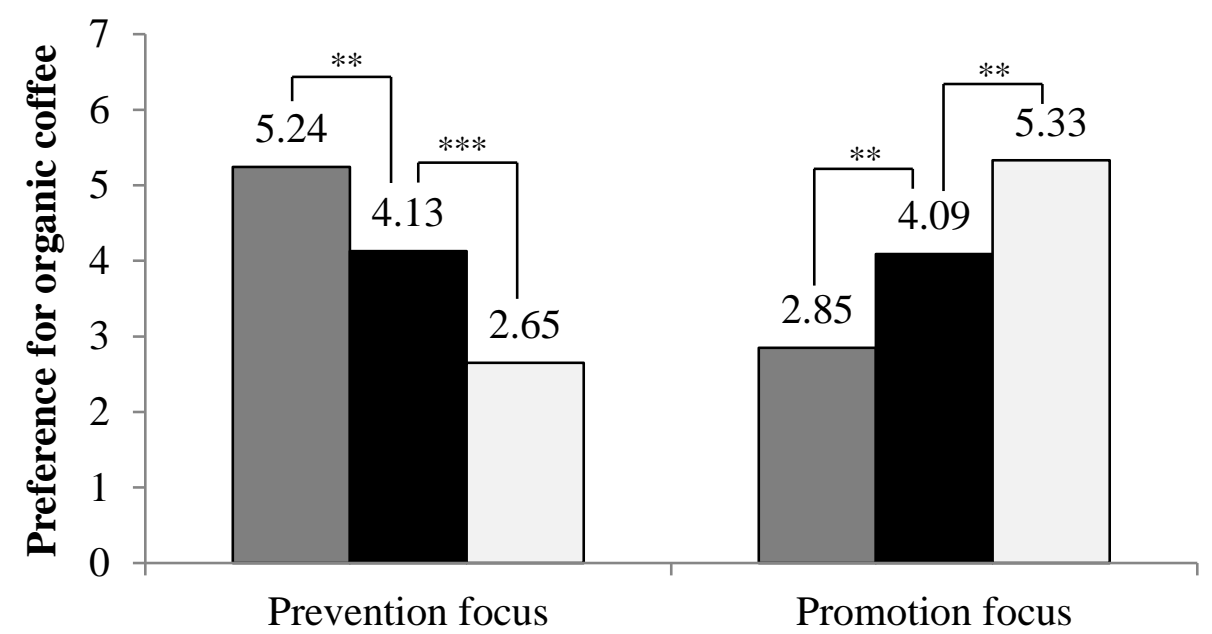

$\square$ First decision moral $\quad$ Control $\quad \square$ First decision immoral

Note:

** $\quad$ Significant at $p \leq .05$

$* * *$ Significant at $p \leq .01$ 
Figure 2: Graphical representation of Study 2 results.

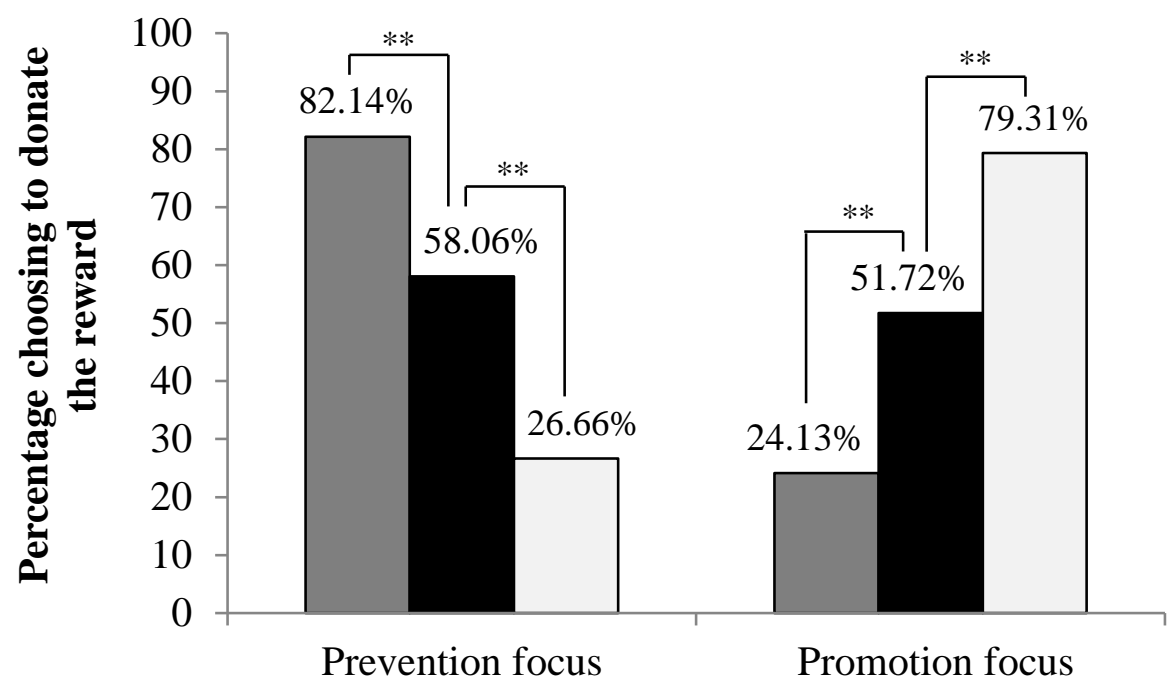

$\square$ First decision moral $\square$ Control $\square$ First decision immoral

Note:

** Significant at $p \leq .05$ 
Figure 3: Graphical representation of Study 3 results.

Panel A: High moral ambiguity

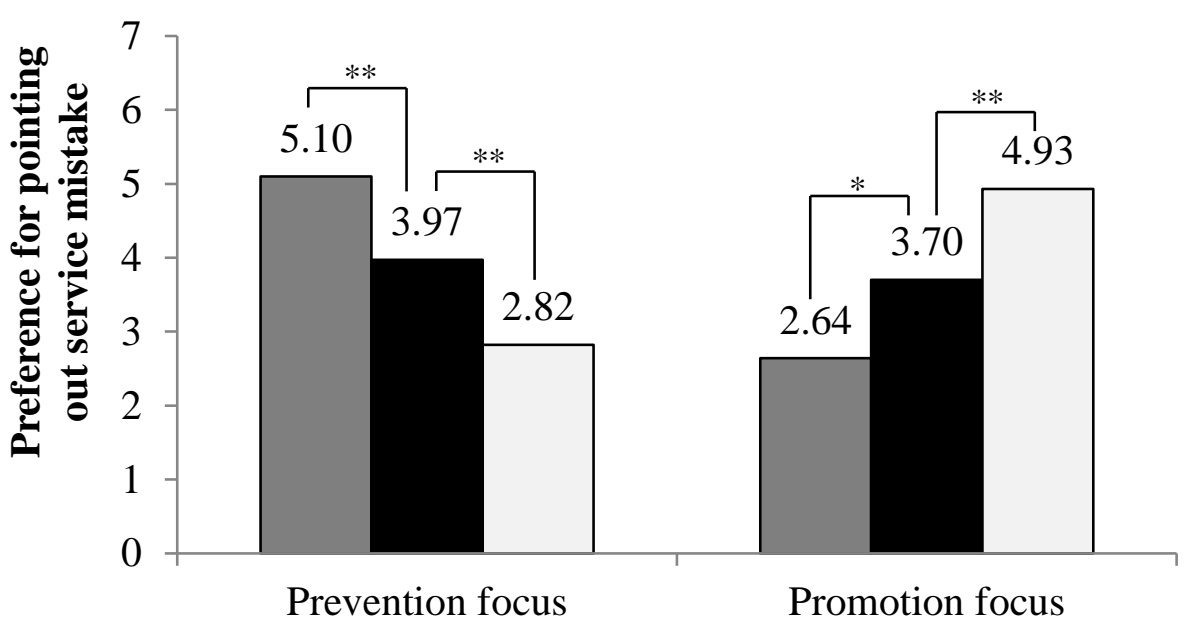

$\square$ First decision moral $\quad$ Control $\quad \square$ First decision immoral

Panel B: Low moral ambiguity

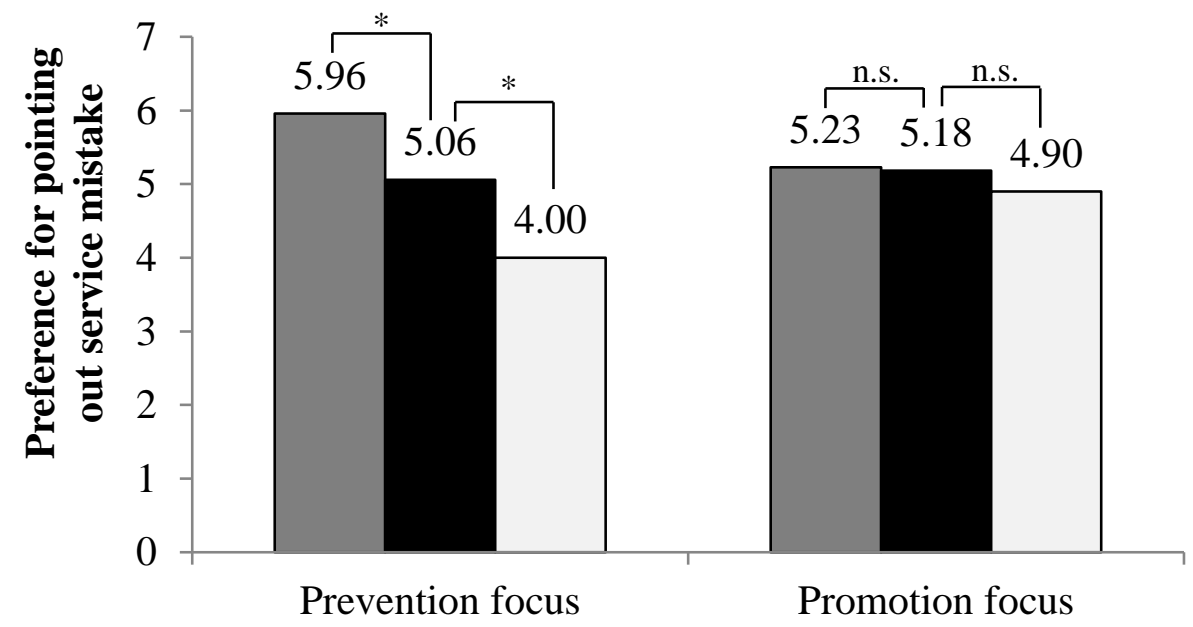

$\square$ First decision moral $\quad$ Control $\square$ First decision immoral

Note:

* $\quad$ Significant at $p \leq .10$

** Significant at $p \leq .05$

n.s. not significant 